\title{
Nitrogen detected TROSY at high field yields high resolution and sensitivity for protein NMR
}

\author{
Koh Takeuchi ${ }^{\# 1,2}$, Haribabu Arthanari ${ }^{\# 3}$, Ichio Shimada ${ }^{1,4,}{ }^{*}$, and Gerhard Wagner $3,{ }^{*}$ \\ ${ }^{1}$ Molecular Profiling Research Center for Drug Discovery, National Institute for Advanced \\ Industrial Science and Technology, Tokyo 135-0063, Japan \\ 2JST, PRESTO, Tokyo 135-0063, Japan \\ ${ }^{3}$ Department of Biochemistry and Molecular Pharmacology, Harvard Medical School, Boston, MA \\ 02115 . \\ ${ }^{4}$ Graduate Schools of Pharmaceutical Sciences, The University of Tokyo, Tokyo 113-0033, Japan \\ \# These authors contributed equally to this work.
}

\section{Abstract}

Detection of ${ }^{15} \mathrm{~N}$ in multidimensional NMR experiments of proteins has sparsely been utilized because of the low gyromagnetic ratio $(\gamma)$ of nitrogen and the presumed low sensitivity of such experiments. Here we show that selecting the TROSY components of proton-attached ${ }^{15} \mathrm{~N}$ nuclei (TROSY ${ }^{15} \mathrm{~N}_{\mathrm{H}}$ ) yields high quality spectra in high field magnets $(>600 \mathrm{MHz}$ ) by taking advantage of the slow ${ }^{15} \mathrm{~N}$ transverse relaxation and compensating for the inherently low ${ }^{15} \mathrm{~N}$ sensitivity. The ${ }^{15} \mathrm{~N}$ TROSY transverse relaxation rates increase modestly with molecular weight but the TROSY gain in peak heights depends strongly on the magnetic field strength. Theoretical simulations predict that the narrowest line width for the TROSY ${ }^{15} \mathrm{~N}_{\mathrm{H}}$ component can be obtained at $900 \mathrm{MHz}$, but sensitivity reaches its maximum around $1.2 \mathrm{GHz}$. Based on these considerations, a ${ }^{15} \mathrm{~N}$-detected $2 \mathrm{D}{ }^{1} \mathrm{H}-{ }^{15} \mathrm{~N}$ TROSY-HSQC $\left({ }^{15} \mathrm{~N}\right.$-detected TROSY-HSQC) experiment was developed and high-quality $2 \mathrm{D}$ spectra were recorded at $800 \mathrm{MHz}$ in $2 \mathrm{hr}$ for $1 \mathrm{mM}$ maltosebinding protein at $278 \mathrm{~K}\left(\tau_{\mathrm{c}} \sim 40 \mathrm{~ns}\right)$. Unlike for ${ }^{1} \mathrm{H}$ detected TROSY, deuteration is not mandatory to benefit ${ }^{15} \mathrm{~N}$ detected TROSY due to reduced dipolar broadening, which facilitates studies of proteins that cannot be deuterated, especially in cases where production requires eukaryotic expression systems. The option of recording ${ }^{15} \mathrm{~N}$ TROSY of proteins expressed in $\mathrm{H}_{2} \mathrm{O}$ media also alleviates the problem of incomplete amide proton back exchange, which often hampers the detection of amide groups in the core of large molecular weight proteins that are expressed in $\mathrm{D}_{2} \mathrm{O}$ culture media and cannot be refolded for amide back exchange. These results illustrate the potential of ${ }^{15} \mathrm{~N}_{\mathrm{H}}$-detected TROSY experiments as a means to exploit the high resolution offered by high field magnets near and above $1 \mathrm{GHz}$.

"Corresponding Authors Gerhard Wagner: Department of Biochemistry and Molecular Pharmacology, Harvard Medical School, 240 Longwood Avenue, Boston, MA 02115, USA. Tel.: (617) 432 3213, Fax: (617) 432 4383, gerhard_wagner@ @ms.harvard.edu; Ichio Shimada: Graduate Schools of Pharmaceutical Sciences, The University of Tokyo, 7-3-1 Hongo, Bunkyo-ku, Tokyo 113-0033, Japan, shimada@iw-nmr.f.u-tokyo.ac.jp. 


\section{Keywords}

Nitrogen detection; TROSY; High field magnet; protein NMR; amide back exchange; deuteration

\section{Introduction}

Heteronuclear NMR experiments that use detection of nuclei with low gyromagnetic ratio $(\gamma)$ and benefit from the slower relaxation properties of ${ }^{13} \mathrm{C}$ and ${ }^{15} \mathrm{~N}$ have recently been proposed to expand the utility of NMR in structural and functional studies of macromolecules (Takeuchi et al., 2012). A variety of experiments have been developed for structure analyses of proteins using ${ }^{13} \mathrm{C}$-direct detection (Arnesano et al., 2005; Bermel et al., 2003; Bermel et al., 2006a; Bermel et al., 2006b; Felli and Brutscher, 2009; Hsu et al., 2009; Lee et al., 2005; Serber et al., 2001; Takeuchi et al., 2010a; Takeuchi et al., 2008) and ${ }^{15} \mathrm{~N}$-direct detection (Gal et al., 2011; Levy and Richter, 1979; Takeuchi et al., 2012; Takeuchi et al., 2010b; Vasos et al., 2006). Since ${ }^{15} \mathrm{~N}$ has the lowest $\gamma$ among NMR active nuclei found in proteins, ${ }^{15} \mathrm{~N}$-direct detection is expected to yield the narrowest NMR resonances (Figure S1), which should help resolving signal degeneracy in high molecularweight or unstructured systems.

Previously, ${ }^{2} \mathrm{H}$-attached amide ${ }^{15} \mathrm{~N}\left({ }^{15} \mathrm{~N}_{\mathrm{D}}\right)$ has been used in ${ }^{15} \mathrm{~N}$-direct detection experiments of proteins based on the perception of the general line-narrowing effect of deuteration (Takeuchi et al., 2012; Takeuchi et al., 2010b; Vasos et al., 2006); here we present that the TROSY (Pervushin, 2000; Pervushin et al., 1997) component of ${ }^{1} \mathrm{H}$-attached amide ${ }^{15} \mathrm{~N}$ (TROSY ${ }^{15} \mathrm{~N}_{\mathrm{H}}$ ) should be observed to maximize the benefit of the low $\gamma$-nuclei detection experiments, both in terms of resolution and sensitivity in high field magnets $>600$ MHz. This approach was experimentally supported by the development of a ${ }^{15} \mathrm{~N}$-detected $2 \mathrm{D}{ }^{1} \mathrm{H}-{ }^{15} \mathrm{~N}$ TROSY-HSQC $\left({ }^{15} \mathrm{~N}\right.$-detected TROSY-HSQC) experiment. We found that the ${ }^{15} \mathrm{~N}$-detected TROSY-HSQC spectrum of a $1 \mathrm{mM}$ protein with a $40 \mathrm{~ns}$ rotational correlation time $\left(\tau_{c}\right)$, which corresponds to $67 \mathrm{kDa}$ protein at $298 \mathrm{~K}$, can be recorded in $2 \mathrm{hr}$ with additional benefits in resolution. The ${ }^{15} \mathrm{~N}$ TROSY effect shows strong magnetic field dependence, and the narrowest line width for the TROSY ${ }^{15} \mathrm{~N}_{\mathrm{H}}$ component can be obtained at $900 \mathrm{MHz}$, whereas the sensitivity reaches its maximum around $1.2 \mathrm{GHz}$. The TROSY ${ }^{15} \mathrm{~N}$ detection will also benefit the study of large systems and intrinsically disordered proteins (IDPs), which often suffer from severe spectral overlap. In addition, unlike conventional TROSY ${ }^{1} \mathrm{H}$ detection, deuteration is not mandatory for the TROSY ${ }^{15} \mathrm{~N}$ detection. Thus, the TROSY ${ }^{15} \mathrm{~N}_{\mathrm{H}}$ detection reported here provides a novel opportunity for macromolecular NMR of proteins that can only be expressed in mammalian or insect cells, or systems that cannot be refolded for amide back exchange.

\section{Results}

Figure 1A shows the calculated transverse relaxation rate $\left(R^{2}\right)$ for TROSY ${ }^{15} \mathrm{~N}_{\mathrm{H}}$ (gray) and deuterium-bound nitrogen, ${ }^{15} \mathrm{~N}_{\mathrm{D}}$, (white) of a protein at indicated magnetic field strengths represented by the corresponding proton frequency. At lower magnetic field, the transverse relaxation is slower for ${ }^{15} \mathrm{~N}_{\mathrm{D}}$; however, this is reversed between $11.7 \mathrm{~T}$ and $14.1 \mathrm{~T}$ (500 
$\mathrm{MHz}$ and $600 \mathrm{MHz}$ in proton frequency; Figure 1A). Henceforth we will use the frequency of proton resonance for the description of field strength. For the system with rotational correlation time of $20 \mathrm{~ns}$ (corresponding to a $33 \mathrm{kDa}$ protein at $298 \mathrm{~K}$ ), the ratio of $\mathrm{R}_{2}$ of TROSY ${ }^{15} \mathrm{~N}_{\mathrm{H}}$ relative to ${ }^{15} \mathrm{~N}_{\mathrm{D}}$ is smallest at a field strength of $1.2 \mathrm{GHz}$ and the relaxation rate of TROSY ${ }^{15} \mathrm{~N}_{\mathrm{H}}$ is 4.3 times smaller than that of ${ }^{15} \mathrm{~N}_{\mathrm{D}}\left(\mathrm{R}_{2}\right.$; TROSY ${ }^{15} \mathrm{~N}_{\mathrm{H}}, 6.7$ $\mathrm{s}^{-1} ;{ }^{15} \mathrm{~N}_{\mathrm{D}} 29 \mathrm{~s}^{-1}$ ) (Figure 1B).

The prime reason for this difference stems from the fact that the relaxation rate of ${ }^{2} \mathrm{H}$ attached ${ }^{15} \mathrm{~N}$ lacks the benefit of ${ }^{15} \mathrm{~N}-{ }^{1} \mathrm{H}$ dipole- ${ }^{15} \mathrm{~N}$ CSA interference, the TROSY effect that dramatically reduces relaxation for ${ }^{1} \mathrm{H}$-attached ${ }^{15} \mathrm{~N}$, and this scales with the field strength reaching a maximum at $900 \mathrm{MHz}$ for the ${ }^{15} \mathrm{~N}-{ }^{1} \mathrm{H}$ TROSY resonances (Figure 1A). The ${ }^{15} \mathrm{~N}$ TROSY effect and associated relaxation gains compared to ${ }^{15} \mathrm{~N}_{\mathrm{D}}$ are rather insensitive to the molecular weight of the systems investigated but depend largely on the magnetic field strength (Figure S2A and S2B). The $\mathrm{R}_{2}$ of TROSY ${ }^{15} \mathrm{~N}_{\mathrm{H}}$ reaches its minimum near $900 \mathrm{MHz}$ where it is $62 \%$ slower than at $500 \mathrm{MHz}$. Importantly, the TROSY reduction in transverse relaxation rates is more effective in ${ }^{15} \mathrm{~N}_{\mathrm{H}}$ compared to ${ }^{1} \mathrm{H}_{\mathrm{N}}$ (Figure S2C vs S2A), since the dipole-dipole interactions from surrounding protons are negligible for ${ }^{15} \mathrm{~N}$ due to its low $\gamma$. This provides the additional advantage that, even at non-deuterated conditions, the closest Ha proton introduces only about $5 \%$ of additional ${ }^{15} \mathrm{~N}-{ }^{1} \mathrm{H}$ dipoledipole contribution to $\mathrm{R}_{2}$ of TROSY ${ }^{15} \mathrm{~N}_{\mathrm{H}}$ for a $20 \mathrm{~ns}$ system at $800 \mathrm{MHz}$ (Figure S3).

Since TROSY ${ }^{15} \mathrm{~N}$-detection is favorable at higher magnetic fields, it would be interesting to estimate how much could be gained in signal height at higher field strengths. The intensity (I) of an NMR experiment is proportional to the amount of induced current in the first point of an FID and is reflected in the peak area $(A)$ of a resonance (or volume in multidimensional experiments) after Fourier transform (FT). If the relaxation during the pulse scheme is ignored, this can be written as

$$
I \propto A \propto \gamma_{\mathrm{e}} \cdot \gamma_{\mathrm{d}}^{3 / 2} \cdot \mathrm{B}_{0}^{3 / 2}
$$

where, $\gamma_{\mathrm{e}}$ and $\gamma_{\mathrm{e}}$ are gyromagnetic ratios for excited and detected nuclei, $\mathrm{B}_{0}$ is the magnetic field strength. In contrast, peak height is the integral over the envelop of the FID and is expected to be proportional to the intensity of signal and inversely proportional to $\mathrm{R}_{2}$.

$$
\mathrm{H} \propto \gamma_{\mathrm{e}} \cdot \gamma_{\mathrm{d}}^{3 / 2} \cdot \mathrm{B}_{0}^{3 / 2} / \mathrm{R}_{2}
$$

The peak height of the TROSY ${ }^{15} \mathrm{~N}_{\mathrm{H}}$ resonance will be at maximum around $1.2 \mathrm{GHz}$ and will be 4.8 times higher at $1.2 \mathrm{GHz}$ compared to $500 \mathrm{MHz}$, if the efficiency in signal detection hardware is assumed to be the same (Figure 1C). The relaxation rate $\mathrm{R}_{2}$ of TROSY ${ }^{15} \mathrm{~N}_{\mathrm{H}}$ for a $20 \mathrm{~ns}$ system is expected to be $6.7 \mathrm{~s}^{-1}$ which is more than two times slower than for proton-decoupled ${ }^{15} \mathrm{~N}_{\mathrm{H}}\left(48 \mathrm{~s}^{-1}\right)$ and ${ }^{15} \mathrm{~N}_{\mathrm{D}}\left(29 \mathrm{~s}^{-1}\right)$. Therefore, even though half of the coherence would be lost by the TROSY-selection schemes, the resultant gain in signal height is substantial. Since the noise level after FT is proportional to the square root of the acquisition length, the signal to noise ratio $(\mathrm{S} / \mathrm{N})$ of a spectrum with fixed acquisition length, which is long enough to allow complete relaxation, would directly reflect the 
relaxation benefits. When the acquisition length is matched to the relaxation rates of detected components (Rovnyak et al., 2004), the benefit in S/N would be proportional to the square root of the gain in signal height.

In order to experimentally observe TROSY ${ }^{15} \mathrm{~N}_{\mathrm{H}}$ resonances with optimal resolution and sensitivity, a ${ }^{15} \mathrm{~N}$-detected $2 \mathrm{D}{ }^{1} \mathrm{H}-{ }^{15} \mathrm{~N}$ TROSY-HSQC $\left({ }^{15} \mathrm{~N}\right.$-detected TROSY-HSQC) pulse sequence was developed, in which the TROSY components in both ${ }^{1} \mathrm{H}$ and ${ }^{15} \mathrm{~N}$ dimensions were recorded for optimal resolution, and proton excitation was utilized for optimal sensitivity (Figure 2). The experiment consists of a simple single transition-to-single transition polarization transfer (ST ${ }^{2} \mathrm{PT}$ ) (Pervushin et al., 1998) from ${ }^{1} \mathrm{H}$ to ${ }^{15} \mathrm{~N}$ for selecting the TROSY component in both dimensions. Importantly, a short recycling delay can be used since we excite ${ }^{1} \mathrm{H}$, and we only have to wait for recovery of the rapidly relaxing ${ }^{1} \mathrm{H}$ spins, which is an advantage over ${ }^{15} \mathrm{~N}$ or ${ }^{13} \mathrm{C}$ excitation schemes. The ${ }^{15} \mathrm{~N}$-detected TROSY is significantly shorter than the ${ }^{1} \mathrm{H}$ detected equivalent, which provides additional benefits (Figure 2).

The ${ }^{15} \mathrm{~N}$-detected TROSY-HSQC experiment was first tested at $800 \mathrm{MHz}$ and $500 \mathrm{MHz}$ instruments on ${ }^{2} \mathrm{H}^{15} \mathrm{~N}^{13} \mathrm{C}$-labeled GB1 in a $\mathrm{D}_{2} \mathrm{O}$ buffer at $286 \mathrm{~K}\left(\tau_{\mathrm{c}}=7 \mathrm{~ns}\right.$ ), in order to experimentally verify the enhancement of the TROSY effect at higher fields (see supplementary discussion for detail). The line widths of the TROSY ${ }^{15} \mathrm{~N}$ signals were substantially narrower than the ${ }^{1} \mathrm{H}$-decoupled ${ }^{15} \mathrm{~N}_{\mathrm{H}}$, anti-TROSY ${ }^{15} \mathrm{~N}_{\mathrm{H}}$, and ${ }^{2} \mathrm{H}$ decoupled ${ }^{15} \mathrm{~N}_{\mathrm{D}}$ resonances at $800 \mathrm{MHz}$ (Figure S4A-C). The narrow line widths are directly reflected in the gain of signal height. In contrast, while benefit from TROSYselection was also observed on a $500 \mathrm{MHz}$ magnet, the ${ }^{2} \mathrm{H}$-decoupled ${ }^{15} \mathrm{~N}_{\mathrm{D}}$ resonances have almost the same linewidth as the TROSY ${ }^{15} \mathrm{~N}_{\mathrm{H}}$ resonances at the low field (Figure S4D). These observations clearly demonstrated the benefit of selecting the TROSY ${ }^{15} \mathrm{~N}_{\mathrm{H}}$ components at higher magnetic field.

Figure 3A left shows ${ }^{15} \mathrm{~N}$-detected TROSY-HSQC spectra of $1 \mathrm{mM}^{2} \mathrm{H}^{13} \mathrm{C}^{15} \mathrm{~N}$-labeled maltose binding protein (MBP) in complex with $\beta$-cyclodextrin $(\beta C D)$ in an $800 \mathrm{MHz}$ instrument at $278 \mathrm{~K}$. The $\tau_{\mathrm{c}}$ of the system, at the above conditions was $40 \mathrm{~ns}$ as deduced by TRACT experiments (Lee et al., 2006). The experiments were performed with a cryogenic TXO probe with a cold ${ }^{15} \mathrm{~N}$ preamplifier. The expected line width of the TROSY ${ }^{15} \mathrm{~N}$ components is $3.5 \mathrm{~Hz}$ at $800 \mathrm{MHz}$. The maximum acquisition time for ${ }^{15} \mathrm{~N}$ dimension was set to $160 \mathrm{~ms}$ in order to make sure the resultant spectra have adequate resolution reflecting their relaxation rates. The actual line widths for dispersed signals in the MBP spectrum were broader than expected $(9.5 \mathrm{~Hz} \pm 2.3 \mathrm{~Hz}$; Average \pm S.D. $)$ with no significant dependence on the secondary structures. The broader line widths are presumably due to incomplete heterounclear decoupling from the $\mathrm{CA}$ and $\mathrm{CO}$, exchange with water, and/or other unaccounted effects in the calculation of relaxation rates such as cross relaxation between amide protons and other remote protons by the oscillation between in-phase and antiphase ${ }^{15} \mathrm{~N}$ coherences in the detecting period (Peng et al., 1991).

As shown in Figure 3, the ${ }^{15} \mathrm{~N}$-detected TROSY-HSQC spectra (left) can be recorded in 2 $\mathrm{hr}$ with a reasonable quality for the $40 \mathrm{~ns}$ system as compared to ${ }^{1} \mathrm{H}$-detected TROSYHSQC spectra (right). Both spectra were recorded with a triple-resonance cryogenic probe 
(TXO) designed for heteronuclear-detection experiments. The probe has cryogenic preamps for ${ }^{15} \mathrm{~N}$ and ${ }^{13} \mathrm{C}$, and carbon/nitrogen detection is on the inner coil. All the resonances that were observed in ${ }^{1} \mathrm{H}$-detected TROSY-HSQC spectrum were also observed in the ${ }^{15} \mathrm{~N}$ detected TROSY-HSQC spectrum, with the exception of the arginine side chains, which are folded in the indirect dimension of the ${ }^{1} \mathrm{H}$-detected spectrum but outside the spectrum width of the direct dimension in the ${ }^{15} \mathrm{~N}$-detected spectrum. The additional advantage of the ${ }^{15} \mathrm{~N}$ detected experiment is that it is not affected by water and water suppression schemes as in the ${ }^{1} \mathrm{H}$-detected experiments. For example, the low-frequency signal in the proton dimension (see slice I in Figure 3A and C) is significantly attenuated in the ${ }^{1} \mathrm{H}$-detected experiment compared to the ${ }^{15} \mathrm{~N}$-detected experiment (see slice II in Figure 3A and C) due to the Watergate solvent suppression schemes (Piotto et al., 1992). There is no loss of signals in ${ }^{15} \mathrm{~N}$-detected spectrum, as the latter does not use any solvent suppression schemes.

Although direct comparison of ${ }^{15} \mathrm{~N}$ and ${ }^{1} \mathrm{H}$ sensitivity is difficult since their electric/thermal noise levels, efficiency of detecting the signals, and effect of $\mathrm{B}_{\mathrm{O}}$ field inhomogeneity would be different for the individual electronic circuits, it is still interesting to compare the relative intensity of these two detection schemes. If one assumes identical noise, efficiency in signal detection, and no $\mathrm{B}_{\mathrm{O}}$ field inhomogeneity, the relative intensity (or peak area after FT) of a straightforward ${ }^{15} \mathrm{~N}$-detected experiment that starts from ${ }^{15} \mathrm{~N}$ magnetization compared to ${ }^{1} \mathrm{H}$-detected experiments is 0.0032 . However, if ${ }^{15} \mathrm{~N}$-detected experiments start with the ${ }^{1} \mathrm{H}$ magnetization, the relative intensity becomes 0.032 . In a ${ }^{15} \mathrm{~N}$-detected TROSYHSQC experiment, proton magnetization is transverse for $5.6 \mathrm{~ms}$ and nitrogen magnetization is transverse for $5.6 \mathrm{~ms}$, compared to a ${ }^{1} \mathrm{H}$-detected experiment where the faster relaxing proton magnetization is transverse for $16.8 \mathrm{~ms}$ (Figure 2). Thus, the pulse scheme is shorter in the ${ }^{15} \mathrm{~N}$-detected system and coherence is transverse in ${ }^{15} \mathrm{~N}$ during half of the time. If we factor in the relaxation losses during this shorter time period for a $40 \mathrm{~ns}(\sim 70 \mathrm{kDa})$ protein, then the relative intensity between ${ }^{15} \mathrm{~N}$-detected TROSY-HSQC and ${ }^{1} \mathrm{H}$-detected TROSYHSQC becomes 0.059 . This is consistent with the experimentally observed relative intensities, and in the peak heights, as the line width for the transposed ${ }^{1} \mathrm{H}$-detected TROSYHSQC spectrum is the same as in the ${ }^{15} \mathrm{~N}$-detected TROSY-HSQC with the same maximal acquired points, and the peak heights would directly reflect the intensity of ${ }^{15} \mathrm{~N}$-detected TROSY-HSQC and ${ }^{1} \mathrm{H}$-detected TROSY-HSQC (Figure 3). It should be noted that the sensitivity for the ${ }^{1} \mathrm{H}$-detected experiments would be slightly higher in a TXI probe. However for samples with physiological salt concentrations, there is no significant difference in ${ }^{1} \mathrm{H}$ sensitivity between our TXO and TXI probes in our instruments.

As discussed above, deuteration is not a strict requirement to benefit from the TROSY ${ }^{15} \mathrm{~N}_{\mathrm{H}}$ detection. In contrast, deuteration is mandatory for the TROSY ${ }^{1} \mathrm{H}_{\mathrm{N}}$ detection. For example, the $\mathrm{H}_{\mathrm{a}}$ proton in an a-helical conformation alone, would accelerate the $\mathrm{R}_{2}$ of TROSY ${ }^{1} \mathrm{H}_{\mathrm{N}}$ by 2.5 -fold, and additional contributions from other remote protons would further enhance the relaxation. Since TROSY ${ }^{15} \mathrm{~N}$ detection is still beneficial for proteins expressed in ${ }^{1} \mathrm{H}_{2} \mathrm{O}$, there is no problem associated with the incomplete ${ }^{1} \mathrm{H}$ back exchange of amides, which often happens for large proteins and hampers the detection of signals from internal amide groups. For example, malate synthetase $\mathrm{G}$ that is recombinantly produced in E.coli with a $\mathrm{D}_{2} \mathrm{O}$ culture media has to be unfolded in $\mathrm{H}_{2} \mathrm{O}$ to ensure complete exchange of amide 
protons. However, this procedure usually reduces the final protein yield due to incomplete refolding efficiencies after the proton back exchange (Tugarinov et al., 2006). Moreover, numerous other proteins cannot be refolded for amide proton back exchange.

This rational was experimentally confirmed by the comparison of the first increment of ${ }^{15} \mathrm{~N}$ detected TROSY-HSQC and ${ }^{1} \mathrm{H}$-detected TROSY-HSQC of $0.5 \mathrm{mM}$ MBP in complex with $\beta C D$ in deuterated (left) and non-deuterated (right) conditions (Figure 4). There was only a modest loss in peak heights in the ${ }^{15} \mathrm{~N}$-detected TROSY-HSQC of the protonated compared to the deuterated sample. In contrast, the peak height of ${ }^{1} \mathrm{H}$-detected TROSY-HSQC was reduced to about one third of that of the deuterated sample. The intensity reduction of ${ }^{15} \mathrm{~N}$ detected TROSY-HSQC is mainly due to relaxation loss during the coherence transfer from proton to nitrogen in the pulse program where the proton magnetization is transverse for 5.6 ms (30\% signal reduction is expected) and ${ }^{2} \mathbf{J}$ and ${ }^{3} \mathbf{J}$ scalar coupling to $\mathrm{Ha}$ and $\mathrm{H} \beta$, respectively (see detail in supplemental discussion). As discussed above, the cross relaxation between amide protons and other protons may cause an additional decay (Peng et al., 1991). Nevertheless, some of the resonances in the ${ }^{15} \mathrm{~N}$-detected TROSY-HSQC spectrum showed increased signal heights at the non-deuterated compared to deuterated conditions (indicated with asterisks), which is presumably due to incomplete ${ }^{1} \mathrm{H}$ back exchange in the deuterated protein.

The benefit of recording the ${ }^{15} \mathrm{~N}$-detected TROSY-HSQC spectrum without deuteration was subsequently verified by a $2 \mathrm{D}$ experiment. For this purpose, we have recorded the ${ }^{15} \mathrm{~N}$ detected 2D TROSY-HSQC spectra of deuterated $\left({ }^{2} \mathrm{H}^{15} \mathrm{~N}^{13} \mathrm{C}\right.$-labled) and non-deuterated $\left({ }^{15} \mathrm{~N}^{13} \mathrm{C}\right.$-labled) $\mathrm{MBP}$ at $0.5 \mathrm{mM}$ (Figure $5 \mathrm{~A}$ and $\mathbf{B}$ ). The spectra for deuterated and nondeuterated MBP were recorded for $2.9 \mathrm{hr}$ and $5.7 \mathrm{hr}$, respectively. Although the average signal height of the non-deuterated MBP is less compared to the deuterated MBP, we see that there are numerous peaks that are observed only in the spectrum of non-deuterated MBP but not in that of deuterated MBP. The spectra of deuterated and non-deuterated MBP were directly compared in Figure 5C. Mapping of the residues that are observed only in the nondeuterated sample clearly indicates that those resonances missing in deuterated sample are from the core of the protein that are missing due to incomplete backbone amide backexchange (Figure 5D). Note that MBP can readily be refolded for easy amide proton backexchange of perdeuterated protein. Thus, the assignments for the whole protein are available (Gardner et al., 1998) to identify the positions of the recovered signals in the structure.

\section{Discussion}

Here we report that direct ${ }^{15} \mathrm{~N}_{\mathrm{H}}$ detection in TROSY experiments of protonated amide groups has multiple benefits for studies of large proteins when studied at high field instruments (>600 MHz). Due to the extremely slow transverse relaxation of the ${ }^{15} \mathrm{~N}_{\mathrm{H}}$ TROSY component the quality of ${ }^{15} \mathrm{~N}-{ }^{1} \mathrm{H}$ correlated spectra comes close to the ${ }^{1} \mathrm{H}$-detected TROSYs. Although less sensitive, the ${ }^{15} \mathrm{~N}_{\mathrm{H}}$ detected TROSY exhibits narrower lines, does not necessarily require perdeuterated samples thus circumventing the amide back-exchange problem, and promises to work for much larger proteins. This approach was experimentally supported by the development of a ${ }^{15} \mathrm{~N}$-detected TROSY-HSQC experiment. The TROSYbased ${ }^{15} \mathrm{~N}$-detected schemes can be incorporated in other ${ }^{15} \mathrm{~N}$-detected experiments and will 
have general benefits by enhancing the resolution in crowded spectra. The ${ }^{15} \mathrm{~N}$ detected experiments can readily be combined with NUS methods to speed up acquisition time (Figure S5).

Since ${ }^{15} \mathrm{~N}_{\mathrm{H}}$ TROSY relaxes slower than the ${ }^{1} \mathrm{H}_{\mathrm{N}}$ equivalent (Figures S2, S6), one can benefit from longer acquisition in the direct ${ }^{15} \mathrm{~N}$ dimension to increase signal height. This benefit is compounded by the use of a smaller spectral width $(\sim 6 \mathrm{ppm})$ in the indirect ${ }^{1} \mathrm{H}$ dimension centered at $8.5 \mathrm{ppm}$. Although the dispersion in the ${ }^{15} \mathrm{~N}$ dimension is almost invariant, ${ }^{1} \mathrm{H}$ dispersion can vary significantly depending on the structural characteristic of the proteins. The sampling efficiency in the indirect dimension becomes even more advantageous for IDPs with a small dispersion in the ${ }^{1} \mathrm{H}$ dimension, and the TROSY-HSQC benefits even more in the ${ }^{15} \mathrm{~N}$ detection mode relative to ${ }^{1} \mathrm{H}$ detection.

The narrower lines of TROSY ${ }^{15} \mathrm{~N}_{\mathrm{H}}$ detection experiments will benefit the study of large systems as well as IDPs, which suffer from severe spectral overlap. It should be noted that the relaxation of TROSY ${ }^{15} \mathrm{~N}_{\mathrm{H}}$ deteriorates least with increasing molecular weight among all nuclei found in proteins (Figure S7). This promises access to much larger systems. Furthermore, the narrower line widths may enable measurement of chemical shifts more accurately, which is important for obtaining structure information from pseudo-contact shifts caused by paramagnetic centers or spin labels (Allegrozzi et al., 2000; Allen and Imperiali, 2010; Banci et al., 2004; Inagaki and Miyazawa, 1980; Keizers et al., 2007). Accurate chemical shift measurements are also important for measuring residual dipolar couplings (Tjandra and Bax, 1997; Tolman et al., 1995; Tycko et al., 2000). Consistent with this notion, ${ }^{13} \mathrm{C}$-detection has been shown to increase the detectability and precision of RDC measurement for broad ${ }^{1} \mathrm{H}$ resonances (Balayssac et al., 2006). In further developments, 2D and 3D TROSY versions of additional ${ }^{15} \mathrm{~N}$ detection experiments can be developed for backbone and side-chain assignment of large proteins.

Our simulations indicate that higher magnetic fields enhance the signal heights of ${ }^{15} \mathrm{~N}$ detected TROSY-HSQC signals compared to lower fields, and signal heights are almost independent of the molecular weight (Figure S7). The benefit of TROSY selection in ${ }^{15} \mathrm{~N}$ detection becomes most substantial around $900 \mathrm{MHz}$ with respect to resolution, and signal heights become optimal around 1.1-1.2 GHz.

Although several strategies were developed to achieve deuteration in eukaryotic expression systems (Kofuku et al., 2014; Miyazawa-Onami et al., 2013; Morgan et al., 2000; Sastry et al., 2011), it is still hard to obtain high levels of (>90\%) deuteration with insect and mammalian cells. Thus, ${ }^{15} \mathrm{~N}$-detected experiments, which are not dependent on deuteration as the ${ }^{1} \mathrm{H}$-detected equivalents (Figure 4), will be beneficial for large systems that can be obtained only by using those eukaryotic expression systems. Moreover, since deuteration is not strictly required for TROSY ${ }^{15} \mathrm{~N}$ detection, there is less need for amide protein back exchange, which will alleviate a most serious problem for NMR studies of large proteins that are expressed in deuterated media (Figure 5). However, the impact of protonation on relaxation rates and the associated line widths in the indirect ${ }^{1} \mathrm{H}$ dimension has to be explored and addressed. Avoiding the traditional time-domain approach and acquiring frequency-based correlations to obtain chemical shift correlation for indirect dimension, 
such as the Hadamard approach (Kupce et al., 2003) would be one possibility. Although multiplet structure due to ${ }^{2} \mathrm{~J}$ and ${ }^{3} \mathrm{~J}$ scalar coupling of ${ }^{15} \mathrm{~N}$ to $\mathrm{Ha}$ and $\mathrm{H} \beta$, respectively, might reduce the effective resolution for non-deuterated proteins, especially for the system with smaller effective molecular weight such as IDPs, selective excitation of amide resonances can be used to further reduce the $T_{1}$ recovery delays (Schanda and Brutscher, 2005). It should be noted that selective decoupling of $\mathrm{Ha}$ and $\mathrm{H} \beta$ resonances would at least partially resolve the resolution losses caused by splitting of signal by the ${ }^{2} \mathbf{J}$ and ${ }^{3} \mathbf{J}$ scalar couplings. Thus, the combination of TROSY, Hadamard (Kupce et al., 2003), SOFAST (Schanda and Brutscher, 2005) and combination of them (Schanda and Brutscher, 2006) can further reduce the measurement time and/or be used for sensitivity gains for ${ }^{15} \mathrm{~N}$-detected TROSY. The problem of enhanced ${ }^{1} \mathrm{H}$ relaxation in ${ }^{15} \mathrm{~N}_{\mathrm{H}}$ TROSY experiments of protonated samples can also be addressed by expressing protein in glucose-deficient $\mathrm{H}_{2} \mathrm{O}$ based $\mathrm{M} 9$, supplemented with ${ }^{2} \mathrm{H}^{13} \mathrm{C}^{15} \mathrm{~N}$-labeled amino acids and nutrients, which result in a sample where the amides are fully protonated and Ca is partially deuterated (Lohr et al., 2003). When considering the effect of ionic strength, the sensitivity factor, $L$, of a cyrogenic probes can be expressed as

$$
\begin{aligned}
& L=\left(1+7.45 \frac{R_{s}}{R_{c}}\right)^{-0.5} \\
& R_{s}=\frac{\pi \omega^{2} \mu^{2} \sigma n^{2} b^{4} l}{32\left(a^{2}+(l / 2)^{2}\right)}
\end{aligned}
$$

where $R \mathrm{~s}, R \mathrm{c}, a, b, l, n, \mu, \omega$, and $\sigma$ are the resistance of the sample, the resistance of the coil, coil radius, sample radius, length, coil turns, the permeability of free space, the Larmor frequency, and the sample conductivity, respectively (Kelly et al., 2002). Since the ${ }^{15} \mathrm{~N}$ frequency is about one tenth of the ${ }^{1} \mathrm{H}$ frequency, loss of sensitivity due to high ionic conductivity is expected to be much less in ${ }^{15} \mathrm{~N}$ - compared to ${ }^{1} \mathrm{H}$-detected experiments.

Direct detection of the ${ }^{15} \mathrm{~N}$ TROSY component holds great promise to study high molecular weight protein, systems with spectral overlap, such as IDPs and this advantage scales with magnetic field strength, especially near and above $1 \mathrm{GHz}$.

\section{Supplementary Material}

Refer to Web version on PubMed Central for supplementary material.

\section{Acknowledgement}

This work was supported by NIH grants GM047467 and AI 37581 to GW and by METI (Grant name: development of core technologies for innovative drug development based upon IT) to IS. This work was also partly supported by JST, PRESTO to KT. Maintenance of NMR instruments was in part supported by NIH grant EB002026. We would like thanks Dominique Frueh, Wolfgang Bermel and Arthur Palmer for useful discussions. 


\section{References}

Allegrozzi M, Bertini I, Janik MBL, Lee Y-M, Liu G, Luchinat C. Lanthanide-Induced Pseudocontact Shifts for Solution Structure Refinements of Macromolecules in Shells up to $40 \AA$ from the Metal Ion. J. Am Chem Soc. 2000; 122:4154-4161.

Allen KN, Imperiali B. Lanthanide-tagged proteins--an illuminating partnership. Curr Opin Chem Biol. 2010; 14:247-254. [PubMed: 20102793]

Arnesano F, Banci L, Piccioli M. NMR structures of paramagnetic metalloproteins. Q Rev Biophys. 2005; 38:167-219. [PubMed: 16674835]

Balayssac S, Bertini I, Luchinat C, Parigi G, Piccioli M. ${ }^{13} \mathrm{C}$ direct detected NMR increases the detectability of residual dipolar couplings. J Am Chem Soc. 2006; 128:15042-15043. [PubMed: 17117827]

Banci L, Bertini I, Cavallaro G, Giachetti A, Luchinat C, Parigi G. Paramagnetism-Based Restraints for Xplor-NIH. J Biomol NMR. 2004; 28:249-261. [PubMed: 14752258]

Bermel W, Bertini I, Felli IC, Kummerle R, Pierattelli R. ${ }^{13}$ C Direct detection experiments on the paramagnetic oxidized monomeric copper, zinc superoxide dismutase. J Am Chem Soc. 2003; 125:16423-16429. [PubMed: 14692785]

Bermel W, Bertini I, Felli IC, Lee YM, Luchinat C, Pierattelli R. Protonless NMR experiments for sequence-specific assignment of backbone nuclei in unfolded proteins. J Am Chem Soc. 2006a; 128:3918-3919. [PubMed: 16551093]

Bermel W, Bertini I, Felli IC, Piccioli M, Pierattelli R. ${ }^{13}$ C-detected protonless NMR spectroscopy of proteins in solution. Prog Nucl Magn Res Spec. 2006b; 48:25-45.

Bohlen JM, Bodenhausen G. Experimental Aspects of Chirp NMR Spectroscopy. J Mag Res A. 1993; 102:293-301.

Felli I, Brutscher B. Recent advances in solution NMR: fast methods and heteronuclear direct detection. ChemPhysChem. 2009; 10:1356-1368. [PubMed: 19462391]

Fujiwara T, Nagayama K. Composite inversion pulses with frequency switching and their application to broadband decoupling. J Mag Res (1969). 1988; 77:53-63.

Gal M, Edmonds KA, Milbradt AG, Takeuchi K, Wagner G. Speeding up direct (15)N detection: hCaN 2D NMR experiment. J Biomol NMR. 2011; 51:497-504. [PubMed: 22038648]

Gardner KH, Zhang X, Gehring K, Kay LE. Solution NMR Studies of a 42 KDa Escherichia Coli Maltose Binding Protein/ $\beta$-Cyclodextrin Complex: Chemical Shift Assignments and Analysis. J Am Chem Soc. 1998; 120:11738-11748.

Hsu S-TD, Bertoncini CW, Dobson CM. Use of protonless NMR spectroscopy to alleviate the loss of information resulting from exchange-broadening. J Am Chem Soc. 2009; 131:7222-7223. [PubMed: 19432443]

Inagaki F, Miyazawa T. NMR analyses of molecular conformations and conformational equilibria with the lanthanide probe method. Prog Nuc Mag Res Spec. 1980; 14:67-111.

Kay L, Keifer P, Saarinen T. Pure absorption gradient enhanced heteronuclear single quantum correlation spectroscopy with improved sensitivity. J Am Chem Soc. 1992; 114:10663-10665.

Keizers PH, Desreux JF, Overhand M, Ubbink M. Increased paramagnetic effect of a lanthanide protein probe by two-point attachment. J Am Chem Soc. 2007; 129:9292-9293. [PubMed: 17608481]

Kelly AE, Ou HD, Withers R, Dötsch V. Low-Conductivity Buffers for High-Sensitivity NMR Measurements. J Am Chem Soc. 2002; 124:12013-12019. [PubMed: 12358548]

Kofuku Y, Ueda T, Okude J, Shiraishi Y, Kondo K, Mizumura T, Suzuki S, Shimada I. Functional dynamics of deuterated $\beta 2$-adrenergic receptor in lipid bilayers revealed by NMR spectroscopy. Angew Chem Int Ed. 2014; 53:13376-13379.

Kupce E, Nishida T, Freeman R. Hadamard NMR spectroscopy. Magnetic resonance in chemistry : MRC. 2003; 42:95-122.

Lee D, Hilty C, Wider G, Wüthrich K. Effective rotational correlation times of proteins from NMR relaxation interference. J Magn Reson. 2006; 178:72-76. [PubMed: 16188473] 
Lee D, Vögeli B, Pervushin K. Detection of $\mathrm{C}^{\prime}, \mathrm{C}^{\mathrm{a}}$ correlations in proteins using a new time- and sensitivity-optimal experiment. J Biomol NMR. 2005; 31:273-278. [PubMed: 15928994]

Levy, G.; Richter, R. Nitrogen 15 Nuclear Magnetic Resonance Spectroscopy. John Wiley \& Sons.; 1979.

Lohr F, Katsemi V, Hartleib J, Gunther U, Ruterjans H. A strategy to obtain backbone resonance assignments of deuterated proteins in the presence of incomplete amide $2 \mathrm{H} / 1 \mathrm{H}$ back-exchange. $\mathrm{J}$ Biomol NMR. 2003; 25:291-311. [PubMed: 12766392]

Miyazawa-Onami M, Takeuchi K, Takano T, Sugiki T, Shimada I, Takahashi H. Perdeuteration and methyl-selective ${ }^{1} \mathrm{H},{ }^{13} \mathrm{C}$-labeling by using a Kluyveromyces lactis expression system. J Biomol NMR. 2013; 57:297-304. [PubMed: 24146206]

Morgan WD, Kragt A, Feeney J. Expression of deuterium-isotope-labelled protein in the yeast pichia pastoris for NMR studies. J Biomol NMR. 2000; 17:337-347. [PubMed: 11014598]

Peng J, Thanabal V, Wagner G. Improved Accuracy of Heteronuclear Transverse Relaxation Time Measurements in Macromolecules. Elimination of Antiphase Contributions J Mag Res. 1991; 95:421-427.

Pervushin K. Impact of transverse relaxation optimized spectroscopy (TROSY) on NMR as a technique in structural biology. Q Rev Biophys. 2000; 33:161-197. [PubMed: 11131563]

Pervushin K, Riek R, Wider G, Wuthrich K. Attenuated T2 relaxation by mutual cancellation of dipole-dipole coupling and chemical shift anisotropy indicates an avenue to NMR structures of very large biological macromolecules in solution. Proc Natl Acad Sci. 1997; 94:12366-12371. [PubMed: 9356455]

Pervushin KV, Wider G, Wüthrich K. Single Transition-to-single Transition Polarization Transfer (ST2-PT) in [15N,1H]-TROSY. J Biomol NMR. 1998; 12:345-348. [PubMed: 21136330]

Piotto M, Saudek V, Sklenar V. Gradient-tailored excitation for single-quantum NMR spectroscopy of aqueous solutions. J Biomol NMR. 1992; 2:661-665. [PubMed: 1490109]

Rovnyak D, Hoch JC, Stern AS, Wagner G. Resolution and sensitivity of high field nuclear magnetic resonance spectroscopy. J Biomol NMR. 2004; 30:1-10. [PubMed: 15452430]

Sastry M, Xu L, Georgiev IS, Bewley CA, Nabel GJ, Kwong PD. Mammalian production of an isotopically enriched outer domain of the HIV-1 gp120 glycoprotein for NMR spectroscopy. J Biomol NMR. 2011; 50:197-207. [PubMed: 21667299]

Schanda P, Brutscher B. Very fast two-dimensional NMR spectroscopy for real-time investigation of dynamic events in proteins on the time scale of seconds. J Am Chem Soc. 2005; 127:8014-8015. [PubMed: 15926816]

Schanda P, Brutscher B. Hadamard frequency-encoded SOFAST-HMQC for ultrafast two-dimensional protein NMR. J Magn Reson. 2006; 178:334-339. [PubMed: 16269260]

Serber Z, Richter C, Dotsch V. Carbon-detected NMR experiments to investigate structure and dynamics of biological macromolecules. Chembiochem. 2001; 2:247-251. [PubMed: 11828451]

Takeuchi K, Frueh DP, Hyberts SG, Sun ZJ, Wagner G. High-resolution 3D CANCA NMR experiments for complete mainchain assignments using Ca direct-detection. J Am Chem Soc. 2010a; 132:2945-2951. [PubMed: 20155902]

Takeuchi K, Gal M, Shimada I, Wagner G. Low $\gamma$-nuclei detection experiments for bimolecular NMR. Rec Dev Biomol NMR. 2012:25-52.

Takeuchi K, Heffron G, Sun ZY, Frueh DP, Wagner G. Nitrogen-detected CAN and CON experiments as alternative experiments for main chain NMR resonance assignments. J Biomol NMR. 2010b; 47:271-282. [PubMed: 20556482]

Takeuchi K, Sun ZY, Wagner G. Alternate ${ }^{13} \mathrm{C}-{ }^{12} \mathrm{C}$ labeling for complete mainchain resonance assignments using $\mathrm{C}^{\mathrm{a}}$ direct-detection with applicability toward fast relaxing protein systems. $\mathrm{J}$ Am Chem Soc. 2008; 130:17210-17211. [PubMed: 19049287]

Tjandra N, Bax A. Direct Measurement of Distances and Angles in Biomolecules by NMR in a Dilute Liquid Crystalline Medium. Science. 1997; 278:1111-1114. [PubMed: 9353189]

Tolman JR, Flanagan JM, Kennedy MA, Prestegard JH. Nuclear magnetic dipole interactions in fieldoriented proteins: information for structure determination in solution. Proc Natl Acad Sci. 1995; 92:9279-9283. [PubMed: 7568117] 
Tugarinov V, Kanelis V, Kay LE. Isotope labeling strategies for the study of high-molecular-weight proteins by solution NMR spectroscopy. Nat Protocols. 2006; 1:749-754. [PubMed: 17406304]

Tycko R, Blanco FJ, Ishii Y. Alignment of Biopolymers in Strained Gels: A New Way To Create Detectable Dipole-Dipole Couplings in High-Resolution Biomolecular NMR. J Am Chem Soc. 2000; 122:9340-9341.

Vasos PR, Hall JB, Kummerle R, Fushman D. Measurement of $15 \mathrm{~N}$ relaxation in deuterated amide groups in proteins using direct nitrogen detection. J Biomol NMR. 2006; 36:27-36. [PubMed: 16967194] 

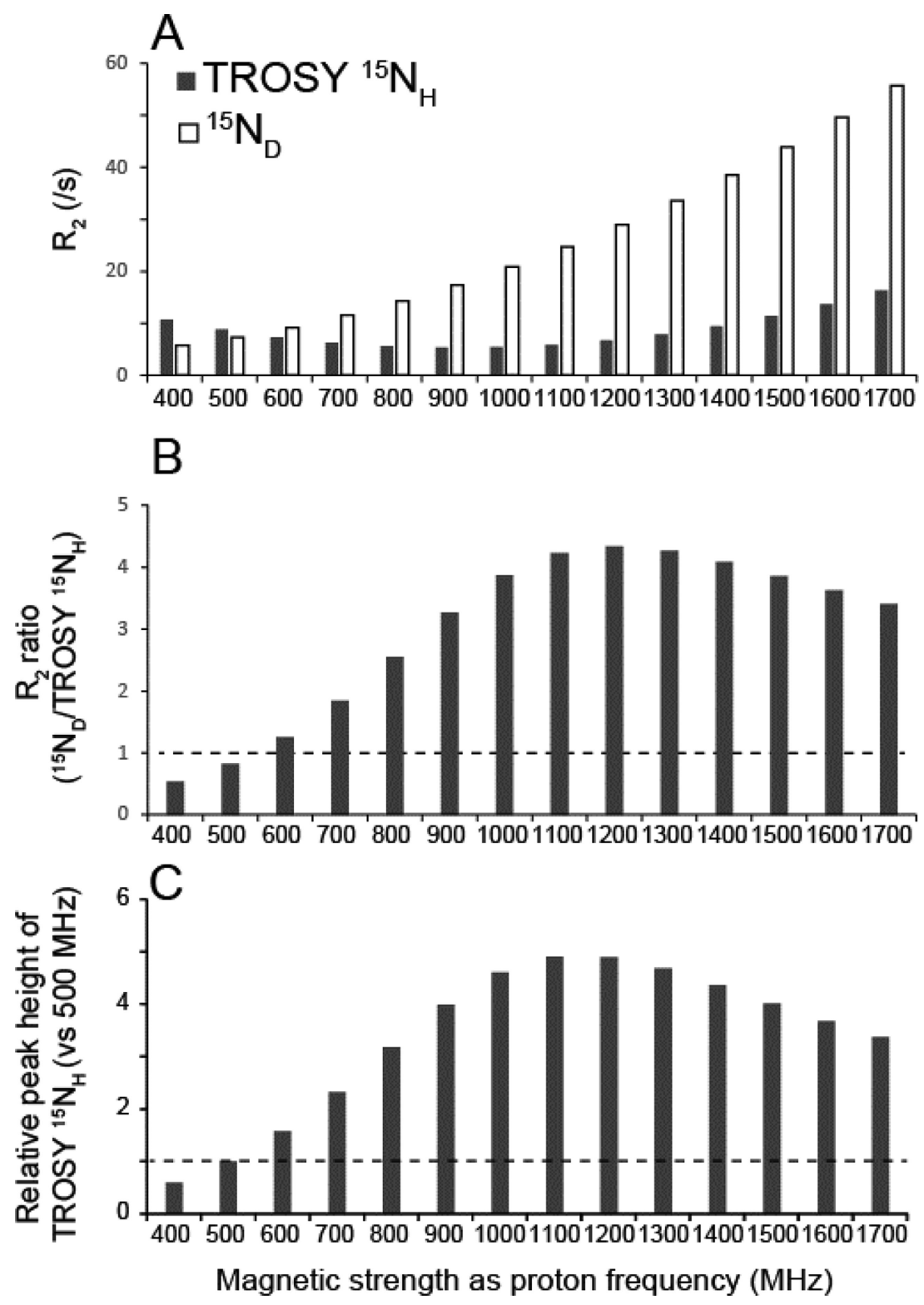

Figure 1. Estimated relaxation rates and relative peak heights of $\operatorname{TROSY}^{15} \mathrm{~N}_{\mathrm{H}}$ at various magnetic field strengths

(A) Calculated $\mathrm{R}_{2}$ for TROSY ${ }^{15} \mathrm{~N}_{\mathrm{H}}$ (gray) and ${ }^{15} \mathrm{~N}_{\mathrm{D}}$ (white) at magnetic field strengths indicated with proton frequency. (B) $R_{2}$ ratio of ${ }^{15} N_{D}$ over TROSY ${ }^{15} N_{H}$ (C) Relative signal heights of TROSY ${ }^{15} \mathrm{H}_{\mathrm{N}}$ resonances relative to $500 \mathrm{MHz}$. The instrumental efficiencies for detecting the resonance are assumed to be the same across spectrometers. The transverse relaxation rates were calculated based on equations (1) and (5) in the supplemental materials and methods. 


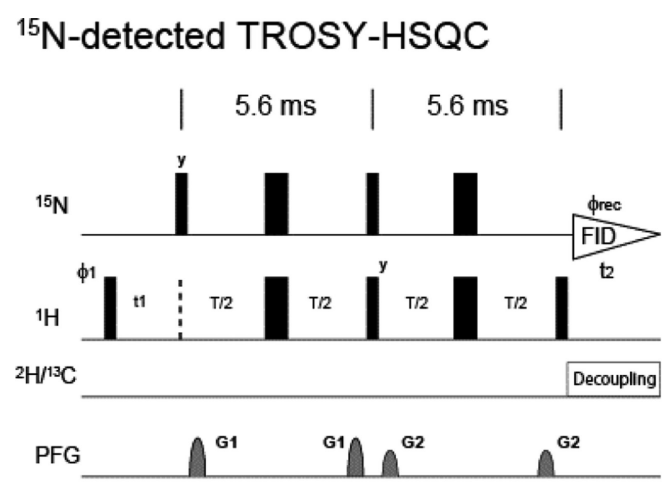

$\phi 1:(y-y x-x) /(-y y x-x) \quad$ фrec: $x-x-y y$

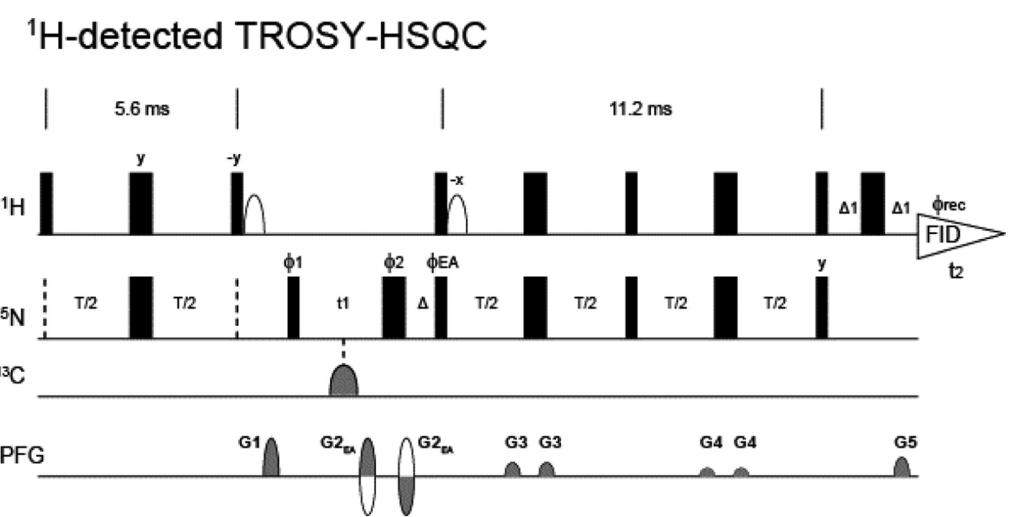

$\phi 1: \mathbf{X},-\mathbf{X} \quad \phi 2: \mathbf{X}, \mathbf{x},-\mathbf{x},-\mathbf{x} \quad \phi r e c: \mathbf{X},-\mathbf{X}$

Figure 2. Pulse sequence of ${ }^{15} \mathrm{~N}$-detected (left) and ${ }^{1} \mathrm{H}$-detected (right) 2D TROSY-HSQC experiments

Narrow and wide rectangular black bars indicate non-selective $\pi / 2$ and $\pi$ pulses, respectively. All pulses are applied along the $\mathrm{x}$-axis unless indicated otherwise. The delays $\mathrm{T}$ were set to $2.7 \mathrm{~ms}$. The phase cycle employed was $\varphi 1=(\mathrm{y}-\mathrm{y} \mathrm{x}-\mathrm{x})$, and $\varphi \operatorname{rec}=(\mathrm{x}-\mathrm{x}-\mathrm{y} \mathrm{y})$ for ${ }^{15} \mathrm{~N}$-detected 2D TROSY-HSQC and $\varphi 1=(\mathrm{x}-\mathrm{x}), \varphi 2=(\mathrm{x} \mathrm{x}-\mathrm{x}-\mathrm{x})$, and $\varphi$ rec $=(\mathrm{x}-\mathrm{x})$ for ${ }^{1} \mathrm{H}$-detected 2D TROSY-HSQC. Phase sensitive detection in the indirect ${ }^{1} \mathrm{H}$ dimension (t1) was obtained by incrementing the phase $\varphi 1$ for ${ }^{15} \mathrm{~N}$-detected 2D TROSY-HSQC and the phase $\varphi 3$ and G2 in an echo-antiecho manner (Kay et al., 1992). The recycling delay was set to $1 \mathrm{~s}$. For ${ }^{15} \mathrm{~N}$-detected 2D TROSY-HSQC, the two sine-shaped pulsed field gradients were applied along the $\mathrm{z}$-axis for $1.0 \mathrm{~ms}$ with maximum intensities of $\mathrm{G} 1=22.5 \mathrm{G} / \mathrm{cm}$, and G2 = $25 \mathrm{G} / \mathrm{cm}$. For ${ }^{1} \mathrm{H}$-detected 2D TROSY-HSQC, the sine-shaped pulsed field gradients were applied along the $\mathrm{z}$-axis for $1.0 \mathrm{~ms}$ with maximum intensities of $\mathrm{G} 1=-15 \mathrm{G} / \mathrm{cm}$, and $\mathrm{G} 2= \pm$ $40 \mathrm{G} / \mathrm{cm}, \mathrm{G} 3=4.5 \mathrm{G} / \mathrm{cm}, \mathrm{G} 4=0.5 \mathrm{G} / \mathrm{cm}, \mathrm{G} 5=8.1 \mathrm{G} / \mathrm{cm}$. Deuterium decoupling was achieved by using WALTZ16 (Shaka et al., 1983) $(1 \mathrm{kHz})$ and carbon decoupling was achieved by using a p5m4 supercycle (Fujiwara and Nagayama, 1988) with an adiabatic CHIRP pulse of 2.5 ms length and 25\% smoothing (Bohlen and Bodenhausen, 1993). 

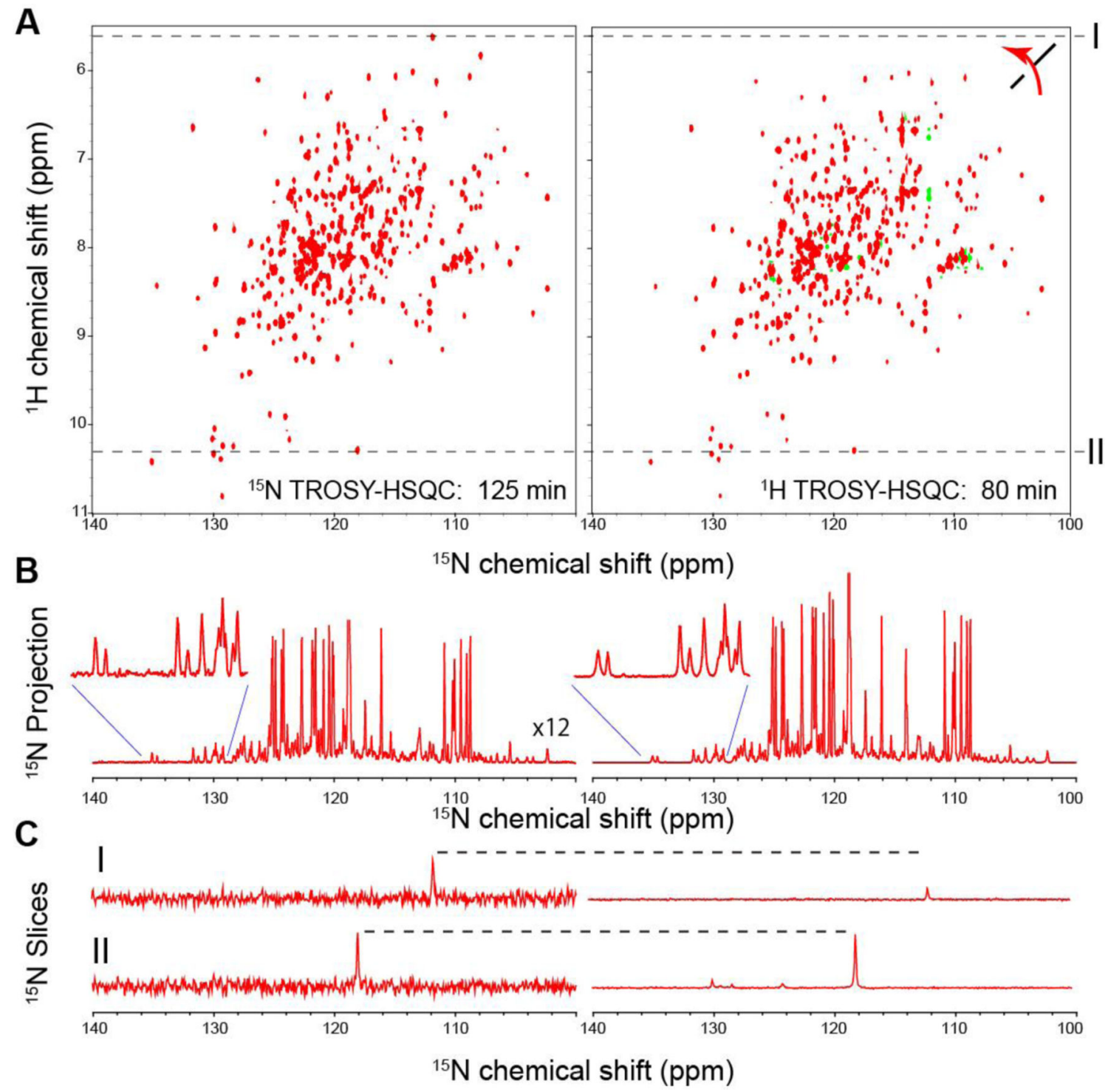

Figure 3. Comparison of ${ }^{15} \mathrm{~N}$-detected TROSY-HSQC (left) and ${ }^{1} \mathrm{H}$-detected TROSY-HSQC (right) of $1 \mathrm{mM}^{2} \mathrm{H}^{15} \mathrm{~N}$-labeled MBP in complex with $2 \mathrm{mM} \beta \mathrm{CD}$ in $800 \mathrm{MHz}$ at $278 \mathrm{~K}$ (A) The ${ }^{15} \mathrm{~N}$-detected TROSY-HSQC was recorded in $125 \mathrm{~min}$, ns=16, F1=348 pts (34ms), $\mathrm{F} 2=1024 \mathrm{pts}(160 \mathrm{~ms})$. The ${ }^{1} \mathrm{H}$-detected TROSY-HSQC was recorded in $80 \mathrm{~min}, \mathrm{~ns}=4$, $\mathrm{F} 1=1024 \mathrm{pts}(160 \mathrm{~ms}), \mathrm{F} 2=1024 \mathrm{pts}(40 \mathrm{~ms})$. (B) ${ }^{15} \mathrm{~N}$ projection of $(\mathrm{A})$. The projection of the ${ }^{15} \mathrm{~N}$-detected experiment is scaled 12 -fold. (C) Two representative cross sections indicated as I and II in (A) are shown. 


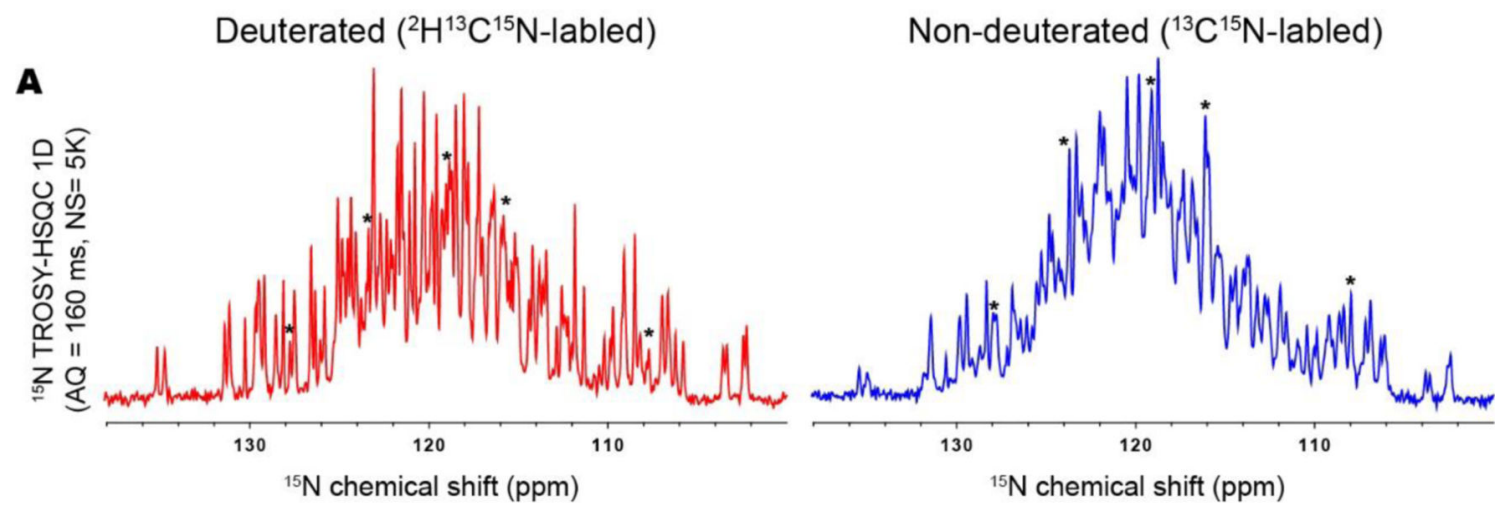

B
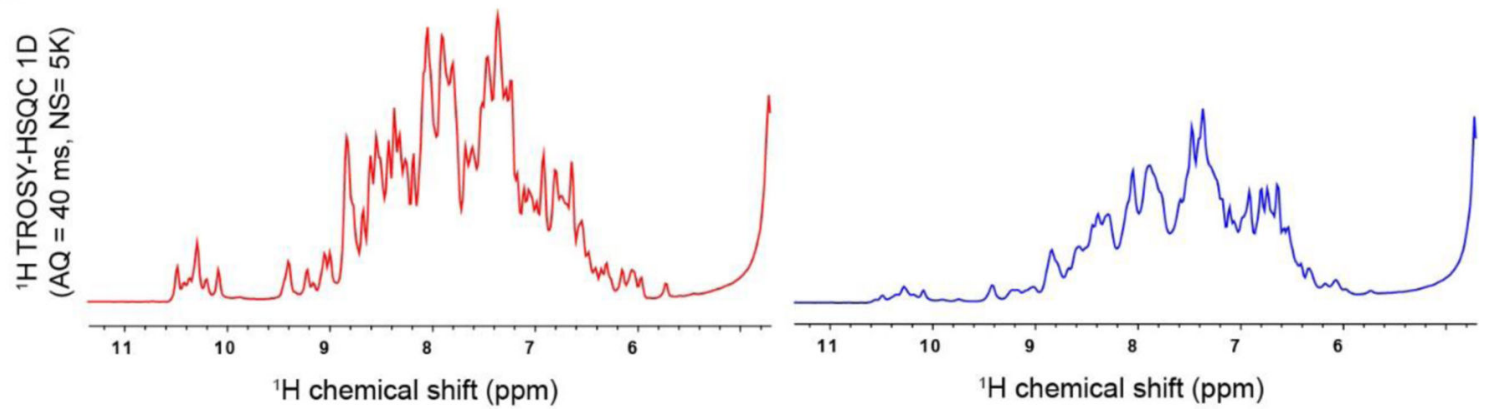

Figure 4. Comparison of (A) ${ }^{15} \mathrm{~N}$-detected TROSY-HSQC and (B) ${ }^{1} \mathrm{H}$-detected TROSY-HSQC of $0.5 \mathrm{mM}$ MBP in complex with $2 \mathrm{mM} \beta \mathrm{CD}$ on a deuterated (left) and non-deuterated (right) protein

(A) The first increment of ${ }^{15} \mathrm{~N}$-detected TROSY-HSQC was recorded in $106 \mathrm{~min}, \mathrm{~ns}=5 \mathrm{~K}$, F2 $=1024$ pts $(160 \mathrm{~ms})$ in $800 \mathrm{MHz}$ at $278 \mathrm{~K}$. (B) The first increment of ${ }^{1} \mathrm{H}$-detected TROSY-HSQC was recorded in $92 \mathrm{~min}, \mathrm{~ns}=5 \mathrm{~K}, \mathrm{~F} 2=1024 \mathrm{pts}(40 \mathrm{~ms})$ in $800 \mathrm{MHz}$ at 278

$\mathrm{K}$. In (A) the resonances that clearly showed higher signal height in the non-deuterated compared to the deuterated sample are indicated by asterisks. 

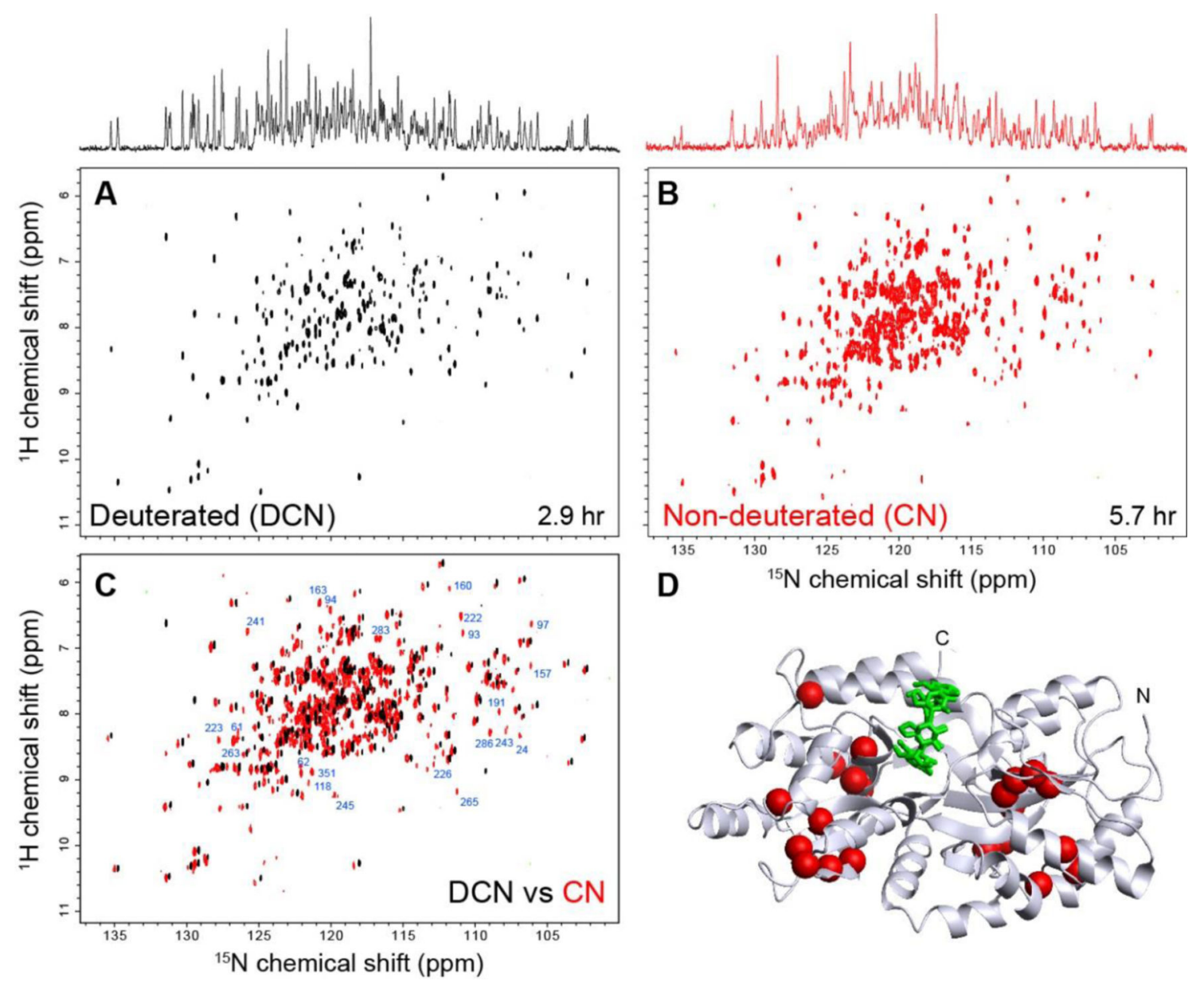

Figure 5. Comparison of 2D ${ }^{15} \mathrm{~N}$-detected TROSY-HSQC of (A) ${ }^{2} \mathrm{H}^{15} \mathrm{~N}^{13} \mathrm{C}$-labled (deuterated) and $(B){ }^{15} \mathrm{~N}^{13} \mathrm{C}$-labled (non-deuterated) $0.5 \mathrm{mM} \mathrm{MBP}$ in complex with $2 \mathrm{mM} \boldsymbol{\mathrm { mCD }}$

Both ${ }^{15} \mathrm{~N}$-detected TROSY-HSQC spectra were recorded with $\mathrm{F} 1=128$ pts $(12 \mathrm{~ms}), \mathrm{F} 2=$ 1024 pts $(160 \mathrm{~ms})$ in $800 \mathrm{MHz}$ at $278 \mathrm{~K}$. The number of scans was set to 64 and 128 in the spectrum of ${ }^{2} \mathrm{H}^{15} \mathrm{~N}^{13} \mathrm{C}$-labled and ${ }^{15} \mathrm{~N}^{13} \mathrm{C}$-labled MBP, respectively. ${ }^{15} \mathrm{~N}$ projections of both spectra are shown on top. (C) Overlay of (A) and (B). The assignments of well-dispersed resonances that were observed only at non-deuterated conditions are indicated. (D) Mapping of residues that are observed only at non-deuterated conditions. The residues annotated in (C) are indicated by spheres in the crystal structure of the MBP- $\beta C D$ complex. 